\title{
Um objeto de aprendizagem para o ensino de Química Geral
}

Bruno dos Santos Pastoriza; Licenciando em Química -UFRGS; eadqui@iq.ufrgs.br Alessandra Faedrich Martins Rosa; Licencianda em Química -UFRGS; eadqui@iq.ufrgs.br

Mara Bertrand Campos de Araujo; Professora - Departamento de Química Inorgânica Instituto de Química -UFRGS; mara@iq.ufrgs.br

Suzana Trindade Amaral; Professora - Departamento de Química Inorgânica - Instituto de Química - UFRGS; stamaral@iq.ufrgs.br

Tania Denise Miskinis Salgado; Professora - Departamento de Físico-Química Instituto de Química - UFRGS; tania.salgado@ufrgs.br

José Cláudio Del Pino; Professor - Departamento de Química Inorgânica - Instituto de Química - UFRGS; aeq@iq.ufrgs.br

\section{Resumo}

Os calouros usualmente encontram dificuldades na disciplina de Química Geral. O objetivo desta proposta é o de contribuir para a melhoria da aprendizagem deles através do desenvolvimento de um hipertexto, que abrange o conteúdo discutido na disciplina oferecida no Instituto de Química da UFRGS para os alunos dos cursos de Química, Engenharia Química e Engenharia de Materiais. Cada assunto é apresentado através de diferentes abordagens: texto escrito e ilustrado, exercícios resolvidos e discutidos, problemas de diferentes graus de complexidade, além de informações complementares onde a relação e a integração com outros assuntos e também com a vida cotidiana podem ser feitas. Os alunos que se dispuseram a utilizar o material o avaliaram positivamente, embora muitos deles ainda apresentem resistência à utilização de métodos que usam estratégias de estudo mediadas por computador, sem a orientação de um professor.

Palavras chaves: química geral, hipertexto, objeto de aprendizagem

\begin{abstract}
A learning object for General Chemistry teaching

Freshman students usually have difficulties in General Chemistry's discipline. The objective of this proposal is to contribute to the improvement of their learning activity, through the development of a hypertext. It comprehends the contents of a discipline that the Chemistry Institute of Federal University of Rio Grande do Sul (UFRGS) offers to the students whose Major is in: Chemistry, Chemical Engineering and Materials Engineering. Each subject is presented through different approaches: written and illustrated texts, solved and discussed exercises, problems with different difficulty grades, and complementary information, where the relation and integration with others subjects and as well with every day life aspects can be done. Those students who used the material made a positive evaluation. However, many of them showed some resistance to methods, which use study strategies mediated by computer, without a teacher to guide them.
\end{abstract}

Keywords: general chemistry, hypertext, learning object

\section{Introdução}

É através da disciplina de Química Geral que o aluno recém admitido na universidade tem o primeiro contato com os conceitos de química (Santos $\mathrm{F}^{\circ}$., 2000), o que confere a essa disciplina uma importância fundamental no embasamento de toda a sua futura aprendizagem na área de Química. Essa é 
uma disciplina que abrange um amplo conjunto de saberes. Os assuntos são abordados em diferentes profundidades, dependendo do curso a que estão dirigidos. Mas uma característica comum é que a maioria dos alunos apresenta o argumento de que a disciplina os confronta com muito conteúdo e pouco tempo para compreendê-los e absorvê-los. Existe então um grande desafio em disciplinas de Química Geral, que é como melhorar o aprendizado dos estudantes.

A experiência dos autores deste artigo que, ao longo dos anos, têm ministrado disciplinas de Química Geral em diferentes cursos de graduação mostra que alguns fatores podem explicar a grande dificuldade que os alunos encontram nessas disciplinas:

1) Heterogeneidade das turmas, ou seja, em cada turma convivem desde alunos com pouco entendimento dos conceitos que foram estudados no ensino médio até alunos que possuem um bom e consistente domínio do assunto.

2) Alguns alunos do curso de Química já citaram o fato da carga horária em física e cálculo ser superior à da Química Geral, o que trás uma certa frustração por ter que dedicar um tempo relativamente menor à química.

3) Dificuldade com o método de estudo continuado que é necessário na universidade. Muitos alunos assistem às aulas e só vão estudar na semana da prova. Neste momento, ou às vezes só com a nota da prova, é que eles percebem que o estudo não foi suficiente. Em geral mesmo após esta constatação ainda é necessário um tempo maior para que ocorra o amadurecimento do estudante e ele então encare os problemas de frente.

As dificuldades encontradas pelos alunos levam a um alto índice de reprovação e quando a forma produtiva de assimilar os saberes não é encontrada ao repetir a disciplina, muitas vezes contribui para a evasão do curso.

Em uma pesquisa sobre a evasão do curso de Química na Universidade de Brasília (Cunha et al., 2001), os próprios alunos pontuaram, com relação a sua permanência no curso, alguns aspectos como, por exemplo, o despreparo para lidar com as diferenças entre o ensino médio e o sistema universitário. Essas dificuldades dos estudantes no momento de transição entre o ensino médio e o universitário também foi objeto de estudo na Holanda, por ocasião da proposição de uma reforma na escola secundária (Groot et al., 2003). Eles consideram importante melhorar essa interface dos níveis de escolaridade em função da falta de motivação, falta de independência, nível de cognição baixo e uma inabilidade dos estudantes para fazer relações com estudos futuros.

Sendo assim, a disciplina de Química Geral, especialmente no curso de Química, têm ainda um papel importante no sentido de reforçar a motivação dos calouros em continuar se dedicando ao estudo da área que eles escolheram para se profissionalizar, mostrando também a importância da Química no desenvolvimento social, industrial e de outras ciências, bem como a problemática do descontrole de suas aplicações (Pliego et al., 2002).

De acordo com Schnetzler (2002), o modelo dominante de ensino nos cursos de graduação universitária continua a ser o modelo transmissão/recepção e uma visão empirista/positivista da Química. Alternativamente aos métodos de ensino centrados na transmissão de conhecimento, tem sido propostos ambientes de ensino onde os alunos são agentes ativos, ambientes cooperativos de aprendizagem, nos quais os estudantes alcançam uma aprendizagem mais efetiva, e desenvolvem logicamente novas idéias por processos que envolvem raciocínio (Hutchinson, 2000; Cooper, 1995; Phelps, 1996). Para o aperfeiçoamento dos processos de ensino e aprendizagem em Química Geral, Francisco et al (1998), recomendam a ampliação do tempo para discussões conceituais em sala de aula, 
estratégia que permitiu que os estudantes identificassem suas deficiências de conhecimento e relacionassem conceitos, organizando-os de modo significativo.

Uma forma de ampliar o tempo para discussões conceituais pode ser através do uso de processos de aprendizagem mediados por computador, permitindo assim vencer um dos desafios na Química Geral, que é motivar os alunos a desenvolver suas habilidades químicas, através da capacidade de relacionar os diferentes conceitos e construir um raciocínio químico.

Assim, com o objetivo de proporcionar mais uma forma de aprendizagem, mais um passo na direção de levar o aluno a enfrentar esses novos desafios de uma forma promissora, está se desenvolvendo um material na forma de um hipertexto, que no futuro irá possibilitar a cada aluno uma alternativa de construção do conhecimento.

O hipertexto consiste em um conjunto de páginas de informação também chamadas nós - interligadas ativamente, de forma a possibilitar consultas imediatas, em uma ordem que é ditada pelo leitor. Essas páginas de informação podem conter palavras, imagens, gráficos, seqüências sonoras, filmes e documentos complexos, que podem, eles mesmos, ser hipertextos. A ligação entre os nós não é linear e, em alguns casos, chega mesmo a possuir conexões em forma de estrela, de modo reticular. Essa estrutura poliierarquizada auxilia a formalização do conteúdo de problemas complexos e pode ser planejada através de diferentes eixos temáticos, elegendo-se os tópicos centrais ao tema do hipertexto e, quando se julgar necessário ampliar $o$ assunto de algum desses tópicos centrais, novos tópicos são produzidos, interligando-os (Eichler e Del Pino, 2006).

Utilizando-se tecnologia de informática na educação, o hipertexto é apresentado com ilustrações (tabelas, desenhos esquemáticos, animações, simulações e fotos) e disponibilizado através da rede mundial de computadores. A Internet alterou a maneira como o conhecimento é adquirido, distribuído e ampliado (Dórea, 2007), possibilitando uma educação mais personalizada, mais flexível e mais efetiva. É também muito apropriada para sanar dificuldades individuais em uma turma com conhecimentos heterogêneos, bem como para educação continuada, uma vez que o material pode ser acessado sempre que necessário. No futuro, pretende-se implementar, na disciplina de Química Geral para químicos, engenheiros químicos e de materiais, uma turma por educação a distância (EAD) para alunos reprovados com conceito D (ou seja, alunos que foram reprovados mas freqüentaram as aulas presenciais desta disciplina em semestres anteriores).

Entretanto, a utilidade do objeto de aprendizagem desenvolvido não se restringe ao curso presencial, pois poderá também servir de base para desenvolver o material didático desta atividade de ensino em um eventual futuro curso de Licenciatura em Química na modalidade a distância, como vem sendo cogitado já há algum tempo pelo Instituto de Química da UFRGS.

O hipertexto em desenvolvimento ainda lembra um livro, porém virtual, tanto na sua apresentação como na sua utilização, ou seja, ele ainda apresenta uma estrutura linear, embora permita uma navegação não linear. Esta é a estrutura tradicionalmente utilizada pelos alunos, ao adquirir conhecimento através de um livro didático. A estrutura não linear favorecida por um hipertexto pode levar o aluno a se perder no processo, pela falta de hábito com essa forma de aquisição de conhecimentos (Silva et al., 2003). A transição para um hipertexto de estrutura não linear deverá, portanto, ser construída coletivamente e aos poucos, uma vez que a química apresenta muito encadeamento de conceitos, que são cumulativos e dependentes. A linearidade de informações também foi priorizada em material 
produzido na área de Engenharia (Pithan, 2007), onde a pesquisa discute a importância de utilizar recursos educacionais de navegação mais linear, atendendo às necessidades de acesso a conteúdos extensos de áreas científicas e tecnológicas. Ela também ressalta a vantagem de disponibilizar conteúdo cumulativo e estruturado, em uma só mídia, consolidando repositórios de objetos educacionais flexíveis, com conteúdos de vários tipos, apresentados em várias formas de representação.

Com o desenvolvimento do sítio de Química Geral espera-se estar no caminho capaz de enfrentar os grandes desafios no ensino dessa disciplina, que são: motivar o aluno a desenvolver suas habilidades e integrar os conceitos químicos, permitindo, então, a construção da ponte entre 0 percebido e 0 imaginado (SILVA et al., 2003).

\section{Método}

O material está sendo desenvolvido como complemento às aulas presenciais de Química Geral teórica dos cursos de Química (Licenciatura, Bacharelado e Industrial), Engenharia Química e Engenharia de Materiais da Universidade Federal do Rio Grande do Sul (UFRGS). Ele se apresenta como um sítio aberto ao qual os usuários têm livre acesso. Quando estiver completo, com todo o conteúdo do programa da disciplina, a sua utilização está planejada para ocorrer através de uma plataforma para ensino a distância, tal como a plataforma Moodle, por exemplo, permitindo um atendimento mais individualizado.

A disciplina que foi escolhida como base para a construção do sítio é a que aborda o assunto em maior profundidade. Sua escolha deveu-se ao fato de que, uma vez que o material esteja preparado, torna-se mais fácil adaptá-lo para utilização em outras disciplinas que não necessitem de tanto aprofundamento. Além disso, ele está sendo pensado também como uma fonte de consulta e utilização para professores do ensino médio.

O acesso é feito ou diretamente através do servidor do Instituto de Química, no endereço www.iq.ufrgs.br/ead/quimicageral, ou via o Projeto CESTA do Centro Interdisciplinar de Novas Tecnologias na Educação (CINTED) da UFRGS.

O sítio está sendo desenvolvido principalmente com os programas Macromedia Dreamweaver e Macromedia Flash.

Com a implantação de um sistema de banco de dados (MySQL) registra-se o monitoramento de acessos e implementa-se o sistema de cadastro. Para que seja possível obter um retorno dos usuários, implantou-se um sistema de monitoramento de acesso e tempo de utilização de cada página do sítio, desde que o usuário coloque o seu nome na abertura do sítio. Há também uma participação voluntária no processo de avaliação do material que é feita através de um sistema de cadastramento. Neste caso, ao início do semestre letivo é enviada uma correspondência eletrônica a cada potencial usuário (alunos de qualquer disciplina do Instituto de Química (IQ) da UFRGS que abranja pelo menos parte do conteúdo desenvolvido), que é então remetido ao endereço www.iq.ufrgs.br/ead/quimicageral/info.php, para preencher um questionário de identificação que ao final o envia ao sítio. Após navegar livremente pelo material, o usuário pode, a qualquer momento, voltar à página principal, clicar no botão "formulário de avaliação" e emitir sua opinião sobre o sítio.

Para a utilização do sítio no ensino a distância, pensamos que apenas a relação máquina-usuário poderia ser muito "fria" e que a inclusão de um personagem poderia abrandar essa característica. Através de um toque de irreverência, este personagem tornaria o sítio um ambiente virtual mais amigável, além de, em certas situações, participar como personagem em animações, 
promovendo um melhor entendimento, assimilação e visualização do conteúdo. Pensando assim, é que foi desenvolvido, em Flash, o personagem do Professor Ludovico Pinacromo (Figura 1).

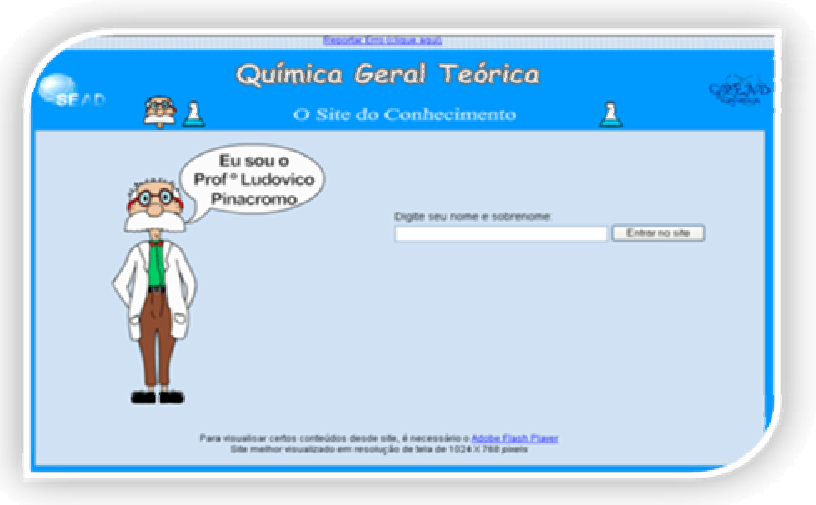

Figura 1 - Página de login no sítio

A cor de fundo do sítio foi escolhida pensando-se no fato de que o usuário permanecerá um tempo longo lendo o material. $O$ branco foi evitado devido ao reflexo, o que acaba tornando a leitura cansativa. Essa cor ficou reservada para fundo de caixas que apresentam equações químicas ou resoluções de problemas, dando-Ihes assim um certo destaque. A cor azul acinzentada foi escolhida por ser uma cor suave, evitando-se a monotonia com uma barra de um azul mais intenso. Nessa barra encontra-se o menu principal que permite ao usuário navegar de uma forma não linear. O menu principal, sempre que necessário, desdobra-se em um ou dois menus secundários. Nas ilustrações procura-se utilizar cores mais vivas.

Desenvolve-se a resolução de problemas e as equações químicas no programa Equation do Word. Evita-se problemas de navegação incorporando-se esse tipo de material em caixas com fundo branco que são coladas como figura. Com esse procedimento previne-se problema de navegabilidade caso o usuário não possua o programa instalado em seu computador.

\section{Resultados}

\section{Desenvolvimento do hipertexto}

O sítio é apresentado pelo professor Ludovico Pinacromo e ao identificarse, o usuário é levado à página inicial onde poderá, no menu à esquerda, selecionar o assunto de seu interesse.

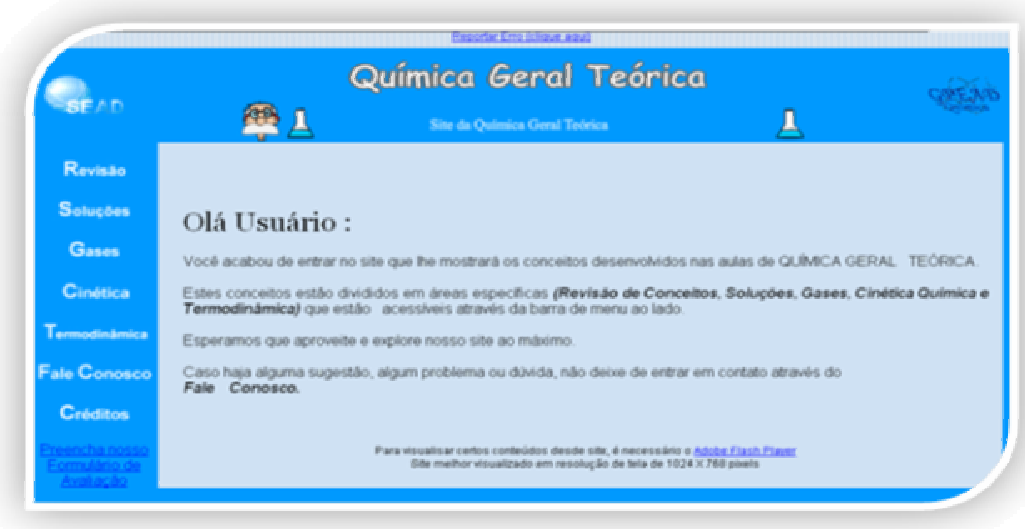

Figura 2 - Página "Home”, mostrando o menu principal. 
Na página seguinte, o professor Ludovico Pinacromo disponibiliza quatro itens que abordam o conteúdo escolhido de diferentes ângulos, a saber: (1) Fundamentos teóricos, (2) Exercícios de Fixação, (3) Testes, (4) Guia dos curiosos. (Figura 3)

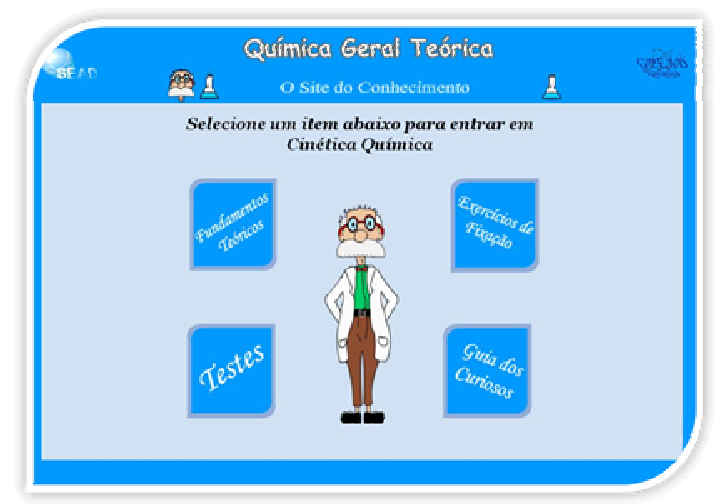

\section{Figura 3 - Página do hipertexto que permite ao usuário escolher de que forma ele quer abordar o conteúdo.}

Em "fundamentos teóricos" o assunto é abordado de forma semelhante àquela apresentada na disciplina presencial, porém mais rico em ilustrações. Fotos e principalmente animações e simulações que auxiliem o usuário na visualização e abstração dos fenômenos abordados foram incorporadas ao hipertexto. Como a animação possui um caráter mais lúdico e por vezes distante da realidade, utilizouse, ainda, fotos de experimentos reais, desenhos esquemáticos ou tabelas, todos com o objetivo de facilitar e implementar a compreensão e fixação do assunto abordado.

Na parte inicial onde uma revisão de conceitos é abordada - Revisão, no menu principal - a não linearidade que o hipertexto permite durante a sua exploração é ainda mais proveitosa, já que o aluno pode se fixar especificamente nas suas deficiências.

Pensando-se em ampliar as oportunidades de experimentação dos alunos, o conteúdo "estados físicos da matéria" tem início com uma animação que deve ser observada pelo usuário e suas observações macroscópicas são então anotadas. Após a leitura do conteúdo teórico é possível editar as observações anotadas anteriormente e por fim conferir com o texto proposto.

Em "exercícios de fixação" são apresentados exercícios simples e diretos com o objetivo de auxiliar na fixação de conceitos, por isso, eles são organizados e identificados com o conteúdo abordado em "fundamentos teóricos". Eles podem ser acessados na página inicial ou no fim de cada página dos "fundamentos teóricos".

A fim de que esta caminhada pelos "exercícios de fixação" não se torne monótona, eles são apresentados de várias formas, que propõem, a cada passo, uma diferente maneira de responder, sempre buscando uma maior interatividade. Alguns exemplos de tipos de exercícios podem ser vistos na Figura 4. Ressalta-se aqui outro ponto: por serem feitos em Flash, estes exercícios possibilitam que o aluno tenha o retorno do seu acerto ou erro. Caso não acerte, é disponibilizada a alternativa de refazer especificamente o exercício em que apresentou dificuldades. 


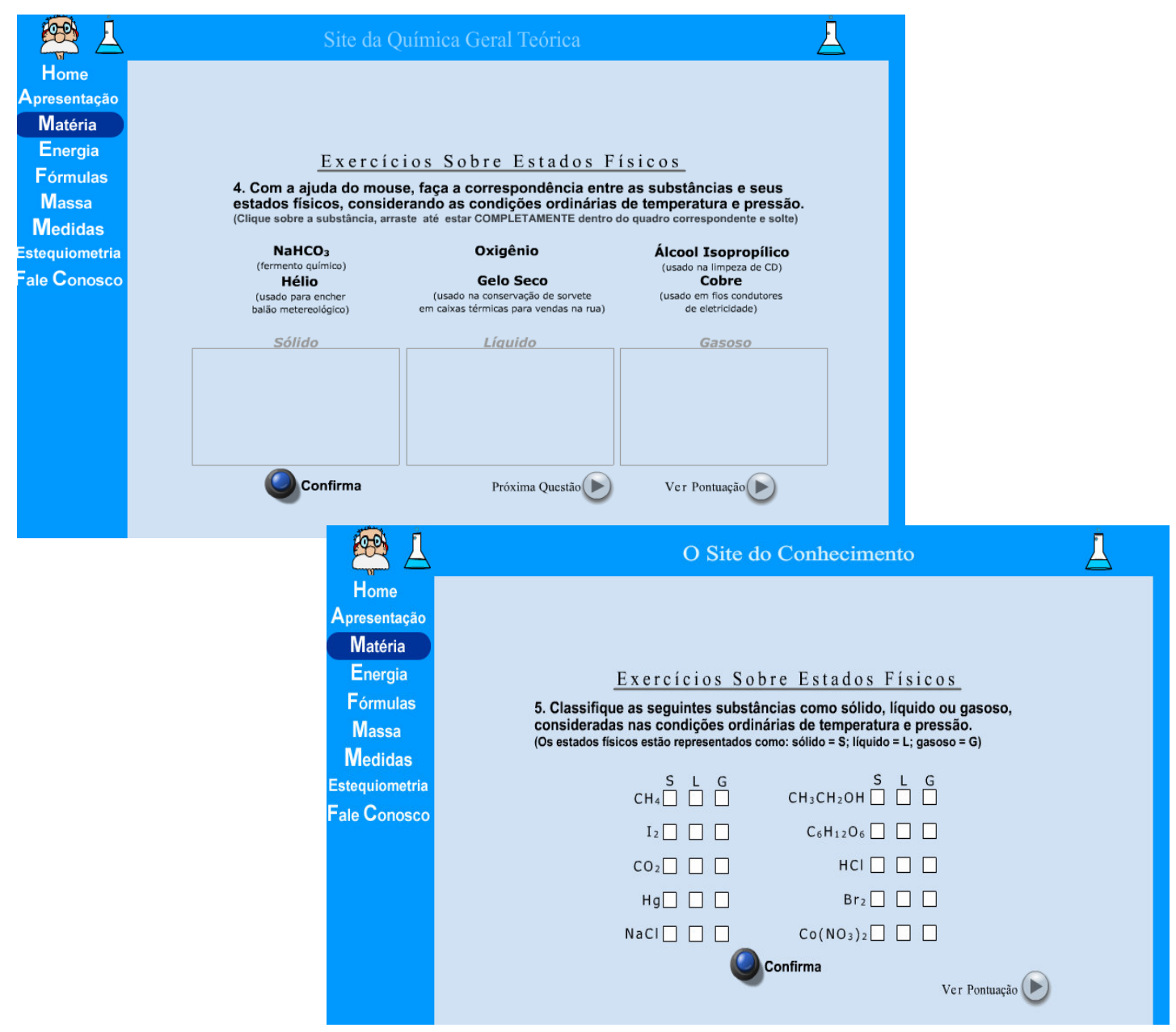

Figura 4 - Exemplos de algumas das modalidades de exercícios de fixação

No item "testes" disponibiliza-se a lista de exercícios, referente à correspondente parte do conteúdo da disciplina de Química Geral teórica, onde os assuntos são abrangidos de forma inter-relacionada, exigindo uma ampliação da capacidade de abstração e interpretação do problema, já que aqui não estão especificados os assuntos a que cada exercício se refere.

Destaca-se que em diferentes momentos tenta-se trazer ao aluno uma certa vivência da Química, onde ele possa correlacionar a química e sua vida. Para isto, é necessário que se vá além dos conceitos simples e das idéias básicas expostas na teoria. Com esse objetivo, foi criado o "guia dos curiosos", onde aquele que explora esta área pode, à sua vontade, se aprofundar em conceitos, comentários, biografias, ferramentas e, propriamente, curiosidades que durante os "fundamentos teóricos" não são possíveis abordar. Para auxiliar nessa navegação, foi criado o ícone do "guia dos curiosos", a interrogação (Figura 5a), que se encontra ao longo destes fundamentos. Ao clicá-la, o usuário será levado ao ponto específico de alguma curiosidade ou informação complementar sobre aquele assunto. Em um caminho contrário, caso o usuário opte por primeiro explorar 0 guia dos curiosos, consta ao final de cada página um ícone referente aos fundamentos teóricos, o livro (Figura 5b), que o levará direto ao ponto em que 
aquela informação está relacionada. Aqui, como pode ser visto, não há um roteiro a seguir, aquele que explora o "guia" é que faz o caminho conforme lhe convém.

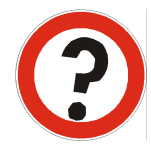

(a)

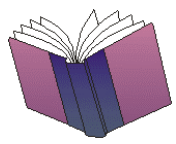

(b)

Figura 5 - (a) Ícone do "guia dos curiosos"; (b) Ícone dos "fundamentos teóricos".

Além disso, com o intuito de disponibilizar e divulgar bons materiais na rede, sempre que possível, incorpora-se objetos de aprendizagem desenvolvidos por outros autores e já disponibilizados na Internet, com o cuidado de solicitar a devida autorização. Links relacionados com o conteúdo, complementares e/ou interessantes são também adicionados ao hipertexto.

\section{Avaliação do hipertexto}

Optou-se por disponibilizar o material, na fase de desenvolvimento, para que os usuários pudessem avaliá-lo ainda na fase de construção, evitando assim que no futuro fosse necessária uma grande correção de rota, uma vez que o material tem que ser interessante e agradável ao público alvo. Só após o sítio chamar e prender a atenção do aluno é que terá início o processo de aprendizagem e para tanto $o$ material tem que proporcionar uma fácil navegabilidade, uma leitura agradável, tem que despertar o interesse do aluno, bem como tem que apresentar o conteúdo de forma clara e diversificada.

O processo de avaliação torna-se possível através do programa de banco de dados (MySQL) que permite o registro das respostas dos questionários de avaliação bem como do acompanhamento da navegação de cada usuário. Este processo está se dando de forma cumulativa porque poucos são os usuários que voluntariamente respondem ao questionário de avaliação ao início ou durante cada semestre. O resultado obtido inicialmente é apresentado na Figura 6, que mostra a percentagem das respostas obtidas no questionário de avaliação. Por questão de clareza da figura foram omitidas as percentagens mais baixas, pouco significativas.

Verifica-se que, quando são avaliados os quesitos físicos do material, ou seja, navegabilidade, leitura e tamanho das páginas, o resultado é bastante favorável. A maioria avaliou positivamente. Na apresentação do sítio, embora a maioria também tenha avaliado favoravelmente, já houve uma pequena queda dos percentuais obtidos. Mas o ponto mais interessante é que as diferenças no domínio de conteúdo entre os usuários refletem-se nos temas da avaliação que se referem mais diretamente ao assunto abordado. Nos três itens finais (interesse que o material desperta, imagens e animações, conteúdo das animações e imagens) as opiniões estão bem mais divididas. 


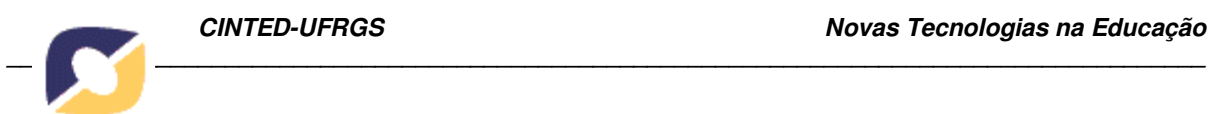

\section{Avaliação do Sítio}

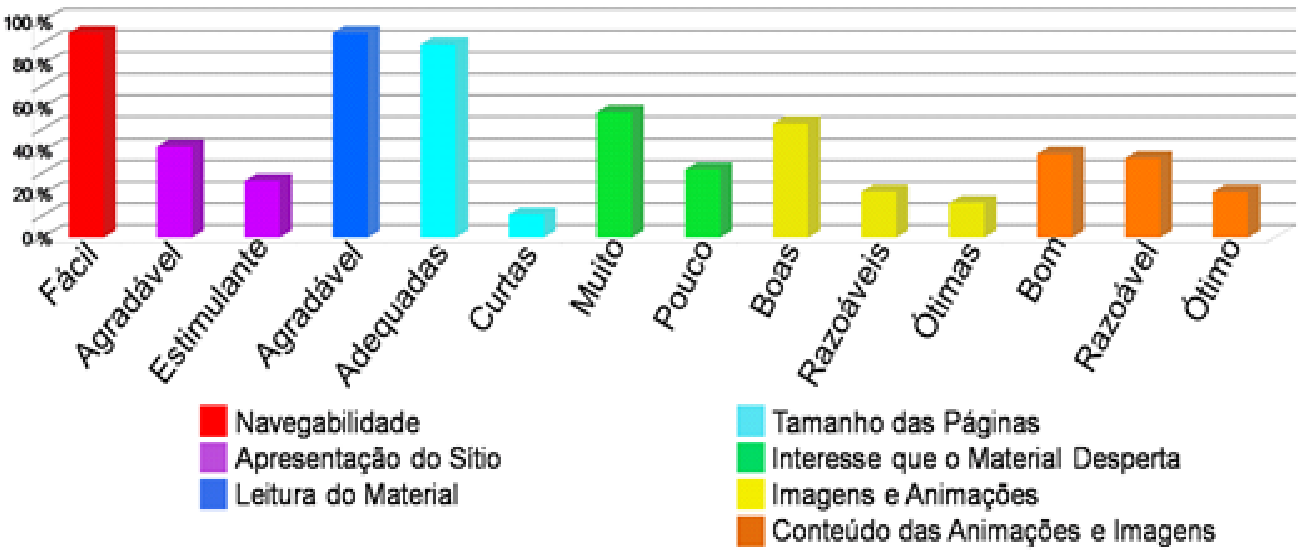

Figura 6 - Resultado da avaliação do sítio.

\section{Conclusão}

O hipertexto encontra-se em desenvolvimento, embora o arcabouço já esteja definido. Exemplos, ilustrações de diferentes tipos e inter-relações serão sempre criadas e adicionadas, com a intenção de ampliar as possibilidades de aprendizagem do aluno e construir um material que possa ser empregado tanto como apoio às atividades de uma disciplina presencial de Química Geral, quanto para servir de base para a futura implementação de uma disciplina/turma de Química Geral a ser oferecida na modalidade a distância.

Quanto à avaliação do sítio pode-se, no momento, inferir que, em geral, os alunos que se dispuseram a utilizar o material o avaliaram positivamente, embora muitos deles ainda apresentem resistência à utilização do método de estudo mediado por computador, sem a orientação de um professor.

\section{Agradecimentos}

À Secretaria de Educação a Distância (SEAD/UFRGS), pela bolsa e auxílio concedidos.

\section{Referências Bibliográficas}

COOPER, M. M. Cooperative learning. Journal of Chemical Education, New Rochelle, v. 72, n. 2, p.162-164, feb. 1995.

CUNHA, A. M.; TUNES, E.; SILVA, R. R. Evasão do curso de química da Universidade de Brasília: a interpretação do aluno evadido. Química Nova, São Paulo, v. 24, n. 1, p. 262-280, jan.-fev. 2001.

DÓREA, F.C.; RODRIGUES, H. S.; LAPOUBLE, O. M. M.; PEREIRA, M. R.; CASTRO, M. S.; FONTES, W. Biochemical view: a web site providing material for teaching biochemistry using multiple approaches. Journal of Chemical Education, New Rochelle, v. 84, n. 11, p.1866-1870, nov. 2007.

EICHLER, M. L.; DEL PINO, J. C. Ambientes virtuais de aprendizagem. Porto Alegre: Editora da UFRGS, 2006.

FRANCISCO, J. S.; NICOLL, G.; TRAUTMANN, M. Integrating multiple teaching methods into a general chemistry classroom. Journal of Chemical Education, New Rochelle, v. 75, n. 2, p.210-213, feb. 1998.

GROOT, D.; HOOGHOFF, H.; VAN HOUT, Ad; WARPS, J. Transition from secondary in The Netherlandas. In: International conference - teaching and 
learning in higher education: new trends and innovations. Universidade de Aveiro, Portugal, 2003.

HUTCHINSON, J. S. Teaching introductory chemistry using concept development. Case studies: interactive and inductive learning. University Chemistry Education, London, v. 4, n.1, p. 3-9, mai. 2000.

PHELPS, A. J. Teaching to enhance problem solving. Journal of Chemical Education, New Rochelle, v. 73, n. 4, p. 301-304, apr. 1996.

PITHAN, F. A.; TIMM, M. I.; FERREIRA $F^{\circ}$., R. C.; PERRY, G. T. O padrão linear de apresentação das informações: uma opção possível. RENOTE - Revista Novas Tecnologias na Educação, Porto Alegre, v. 5, n. 1, jul. 2007. Disponível em: http://www.cinted.ufrgs.br/renote/jul2007/artigos/2aFlavia.pdf

PLIEGO, O. H.; ODETTI, H.; ORTOLANI, A. Los programas de química em la Universidad: comentários e perspectivas. Educación Química, Ciudad de Mexico, v. 13, n.1, p. 20-27, jan-mar. 2002.

SANTOS $F^{\circ}$, P. F. Uma disciplina teórica de química para os alunos ingressantes no curso de graduação em química. Química Nova, São Paulo, v. 23, n. 5, p 699-702, set.-out. 2000.

SCHNETZLER, R. P. Concepções e alertas sobre formação continuada de professores de química. Química Nova na Escola, São Paulo, v.16, p. 15-20, nov. 2002

SILVA, S. M. da; EICHLER, M. L.; DEL PINO, J. C. As percepções dos professores de química geral sobre a seleção e a organização conceitual em sua disciplina. Química Nova, São Paulo, v. 26, n. 4, p. 585-594, jul.-ago. 2003. 